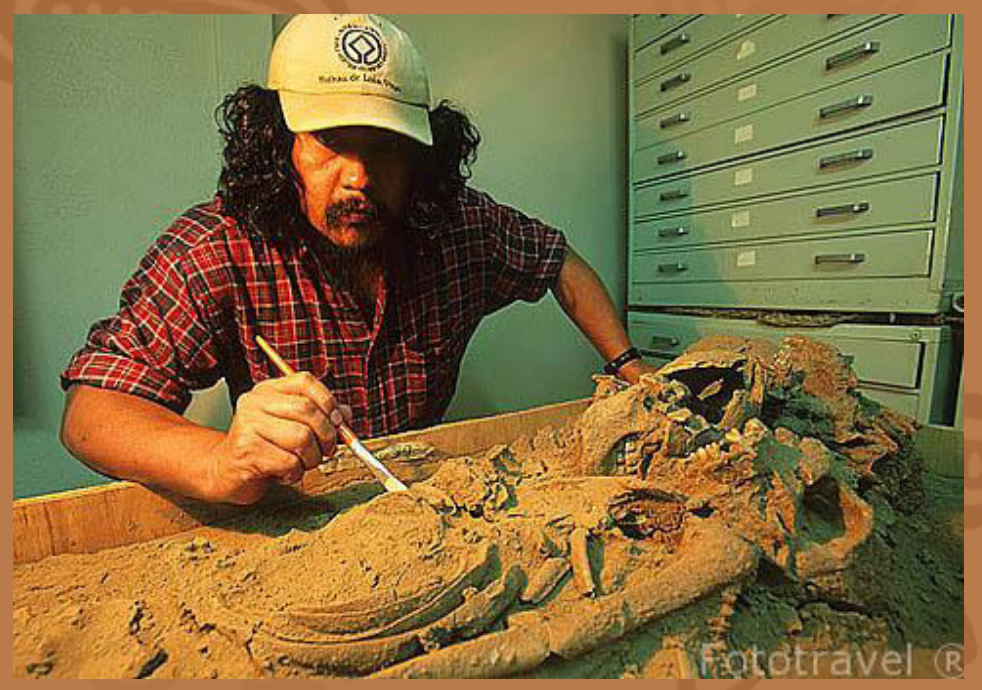

Portada: El trabajo de la antropología física en Nicaragua a sido importante para el análisis de las sociedades prehispánica.

Foto: Fototravel

\title{
Desarrollo de la
} antropología fisjica, un aporte a la descolonización cultural

Rutas de la Antropología Nicaragüense 


\title{
Desarrollo de la antropología física, un aporte a la descolo- nización cultural en Nicaragua'
}

\section{Development of physical anthropology, a contribution to cultural decoloni- zation in Nicaragua}

\author{
Ramiro García Vásquez \\ Consultor independiente \\ Biólogo, especialista en Antropología Física y Arqueología \\ ID Orcid: http://orcid.org/0000-0003-2186-5452 \\ mamutsrgv@yahoo.es
}

\section{Resumen}

El desarrollo de la Antropología Física en Nicaragua tiene aproximadamente 30 años, sus orígenes están en las investigaciones del Departamento de Antropología del Museo Nacional de Nicaragua, cuando la Sra. Leonor Martínez de Rocha entonces directora del Museo, decidió contratar un profesionista en Biología para que se hiciera cargo de los análisis de restos etnozoológicos y etnobotánicos que se encontraban en los depósitos arqueológicos. Doña Leonor había trabajado desde muy joven con Don Diocleciano Chávez, Fundador de la Colección del Museo Nacional y él había hecho un reporte periodístico el 23 de enero de 1920 donde informa del hallazgo de restos humanos momificados encontrados en Punta La Cimarrona, Península de Chiltepe-Managua. Este es uno de los primeros hallazgos vinculados a la Paleoantropología en Nicaragua. A partir de la década del 90 fue posible aplicar las técnicas de la Antropología Física para el estudio y caracterización de las poblaciones originarias que se emplazaron en nuestro territorio, se ha podido estudiar una muestra osteológica que data desde el Periodo Holoceno hasta 1856, reconstruyendo sus patrones de asentamientos, alimenticios, el sistema de creencias, características físicas -biológicas y sus sistemas de organización social. Los resultados obtenidos a lo largo de estos 30 años han estructurado esta ponencia en la que se transmitirán elementos de la verdadera historia de nuestros antepasados, la historia que nos han negado, la reconstrucción descolonizada de nuestras raíces culturales ancestrales.

Palabras claves: Antropología física, análisis de contextos, laboratorio, reconstrucción y descolonización cultural.

\section{Abstract}

The development of Physical Anthropology in Nicaragua is approximately 30 years old, its origins are in the investigations of the Department of Anthropology of the National Museum of Nicaragua, when Mrs. Leonor Martínez de Rocha, then director of the Museum, hired a professional in Biology to to take charge of the analysis of ethnozoological and ethnobotanical remains found in archaeological deposits. Doña Leonor had worked from a young age with Don Diocleciano Chavez, Founder of the National Museum Collection and he had made a journalistic report on January 23, 1920 where the information of the finding of mummified human remains found in Punta La Cimarrona, Chiltepe Peninsula - Managua This is one of the first findings linked to Paleoanthropology in Nicaragua. From the 90's it was possible to apply the techniques of Physical Anthropology for the study and characterization

Ponencia preparada para el XII Congreso Centroamericano de Antropología, Managua, 11 al 14 de noviembre de 2019. 
of the original populations that were located in our territory, an osteological sample dating from the Holocene Period until 1856 has to be studied, reconstructing its settlement patterns, food, the belief system, physical-biological characteristics and their social organization systems. The results obtained over these 30 years have structured this presentation in which elements of the true history of our ancestors will be transmitted, the history they have denied us, the decolonized reconstruction of our ancestral cultural roots.

Keywords: Physical anthropology, context analysis, laboratory, reconstruction and cultural decolonization.

\section{Introducción}

Este texto surge para compartir los resultados de las investigaciones de Antropología Física en Nicaragua, que tienen como eje fundamental reconstruir las características bioantropológicas, raíces e identidad cultural de nuestros ancestros y ancestras. Este artículo contiene un hiato de información que ha resultado de hurgar las evidencias osteológicas registradas en los trabajos de campo y los análisis de laboratorio. Esta muestra procede de diferentes zonas de enterramientos precolombinos, donde se recolectó abundantes fracciones esqueléticas consistentes en más de 400 individuos pertenecientes a nuestros antepasados, Mayagnas, Lencas, Chondalt, Chorotegas, Nicaraos, Sutiabas; quienes fueron los verdaderos conquistadores y constructores de nuestra cultura ancestral, además de varias osamentas perteneciente al mal llamado periodo colonial e independiente. Los restos humanos pueden proporcionarnos abundante información acerca de las sociedades pretéritas y de hecho, ninguna reconstrucción social puede considerarse completa sin un examen de la estructura física y de la salud de la comunidad.

El material osteológico puede así mismo proporcionar interesante información de una índole más especializada tal como los efectos del medio ambiente en las poblaciones modernas y antiguas, o la evolución de las enfermedades. Para emprender esta labor científica de hacer Antropología Física en los restos humanos precolombinos era necesario despertar el interés por la osteología en general, además, estar familiarizado con la Zoología Comparativa, lo cual permite identificar y clasificar taxonómica y anatómicamente los restos osteológicos. Una de las primeras actividades que realicé para emprender estos estudios fue buscar literatura vinculada a la arqueología de la muerte en país, pero raramente solo me encontré un reporte sobre esta temática que describe el hallazgo de los restos humanos registrados en un cementerio precolombino en la Isla de Ometepe, realizado por Wolf Haberlang, arqueólogo de origen alemán, después la información literaria básicamente era nula.

Inmediatamente se me vino a la memoria una serie de incógnitas como: ¿Qué hicieron los investigadores con las osamentas humanas que aparecían en las excavaciones?, ¿Por qué no hay análisis de las muestras osteológicas?, ¿Cuánta información científica se perdió al no realizar estudios en los restos humanos? ¿Qué tipo de tratamientos recibieron los restos humanos exhumados de las tumbas y que información recibieron las comunidades originarias? Los huesos, por regla general, siguen constituyendo un problema para los arqueólogos, aun cuando el esqueleto humano represente una materia de investigación no menos fructífera que la cerámica, los metales, artefactos líticos o cualquier otro material cultural encontrado en un sitio prehistórico.

Desde hace más o menos 30 años, se comenzó a recolectar todas las muestras osteológicas humanas y faunísticas procedentes de los 
yacimientos, así se formó la colección de especímenes sobre los cuales se hicieron las investigaciones y los análisis de laboratorio que proporcionaron una diversidad de información vinculada a la bioantropología de las sociedades que nos antecedieron. Para este trabajo también contamos con bibliografía actualizada y con una colección de referencia osteológica tanto humana como faunística. Entonces visioné que desde la Antropología Física podía hacer un verdadero aporte a la interpretación y reconstrucción de la verdadera cultura e historia de nuestros pueblos ancestrales, y aportar a la línea de las teorías de la descolonización cultural en América Latina, que ha venido tomando fundamentación en el último siglo, con las epistemes defendidas por filósofos, sociólogos y antropólogos, de las regiones Sur, Andina, Caribe y Mesoamérica, que para nuestros pueblos originarios es el Abya Yala, que significa iLa Tierra donde corre la sangre!.

La Antropología Física me ha permitido reconstruir los patrones socioculturales, económicos y políticos de las sociedades que se vinieron desarrollando desde por los menos 8000 años cuando llegaron los humanos de Acahualinca hasta 1550, periodo de tiempo en el cual inician los primeros oleajes invasores del Continente europeo, sin embargo, el colonialismo que duró apenas un poco más de 300 años no puede pretender siquiera borrar una cultura cuyas raíces tienen 8000 años. Lo más importante de la Antropología física es que permite recuperar pruebas tangibles de la grandiosidad de nuestros pueblos originarios y esto, sin duda aporta a la descolonización cultural y mental de nuestro pueblo actual.

\section{Antropología Física o biológica}

Quiero iniciar con el origen de la palabra Antropología que se deriva, etimológicamente de la raíz griega anthropo, que significa "hombre" y de la terminación logía, cuyo significado es "Ciencia". Por lo tanto, la antropología es la Ciencia que estudia al hombre, así como sus obras. El término de Antropología física es usado desde el siglo XIX y aceptado por la UNESCO que le confiere la cualidad de ser un gran campo de estudio. Se trata del estudio biológico de las poblaciones en el espacio y en el tiempo. La evolución de esta materia ha hecho que también reciba el nombre de Antropología biológica. El antropólogo también estudia las causas que han provocado esa diversidad Genética de poblaciones. Estos datos vinculados con la antropología física y cultural de los pueblos originarios nos sugieren que descendemos de una misma matriz biocultural de la cual debemos formar nuestra identidad centroamericana. La divulgación de estas investigaciones será un hecho de mucha relevancia para el desarrollo científico y sociocultural de nuestros pueblos. El fenómeno humano es de gran complejidad y para su correcta comprensión debe ser abordado a diversos niveles. El hombre es en todo momento una entidad biológica, pero la historia natural de esta entidad biológica es absolutamente incomprensible si no se da cuenta del fenómeno cultural. El hombre es un ser cultural, pero este ente cultural es incomprensible sin un cierto conocimiento de su historia. Ahora tenemos un ser cultural, biológico e histórico, que por tal complejidad requiere de un manejo especializado en cada nivel.

\section{Contexto arqueológico - ¿Que nos di- cen los huesos?}

Los restos óseos son una fuente importante para el conocimiento de las condiciones de vida de los integrantes de una población. El análisis de las enfermedades más comunes en una población, el patrón que sigue una enfermedad o una lesión refleja su herencia, clima, dieta y actividades, es decir, su cultura en general parafraseando a F. Márquez 1996. Durante la vida el ser humano sufre cambios que no son observables a simple vista, pero que dejan huella en el sistema óseo, lo cual coadyuva a conocer cuáles fueron las enfermedades o posibles patologías sufridas, así como el tipo de actividades al que fue some- 
tido el cuerpo durante la vida. El análisis de los datos obtenidos mediante el estudio de las osamentas humanas conduce a conocer detalles sobre la relación individuo-sociedad-medioambiente-salud-enfermedad.

En las investigaciones arqueológicas es importante conocer y estudiar el medio natural dentro del cual vivió y se desarrolló un grupo cultural determinado. En el estudio del hábitat de una región o una zona arqueológica dada, es necesario tener en cuenta como aspectos fundamentales, el paisaje y los recursos naturales del lugar.

Los registros de yacimientos paleontológicos, paleoantropológicos y arqueológicos en Nicaragua han permitido reportar sitios desde el Holoceno, que datan desde 6000 a.J.C. hasta 1550 d.J.C, que es el contacto con los españoles. El Yacimiento más importante en el Pacífico es Acahualinca, en Managua, y en el Caribe, Angi en Monkey Point. RACS, otro sitio muy temprano se reporta a la orilla de la laguna de Tiscapa, también en la ciudad capital, donde los estudios sugieren la existencia de un poblamiento que data de (1500 - 2000 años a.J.C.) y probablemente fueron los primeros agricultores de la zona. (Lange, 1995).

Colín Renfrew (Moore, 1995: 719) plantea que la invención de la agricultura posiblemente vinculó a las poblaciones humanas a lugares determinados, poniendo fin a los procesos de etnogénesis. Nuestras poblaciones aborígenes que se asentaron en el territorio nacional son un ejemplo de los grupos de agricultores sedentarios atados a la abundancia de recursos hídricos, florísticos y faunísticos que les proporcionaba la cercanía de los lagos Xolotlán y Cocibolca, los ríos, las lagunas, las costas marinas y las fértiles tierras de origen volcánico y otros factores ambientales como el clima permitieron la adaptación y desarrollo de las sociedades pretéritas en nuestra geografía. O bien como lo explica Brothwell (1993), el entorno en que se encuentran puede contribuir a solucionar de- terminados problemas, el tipo de túmulo puede indicar el periodo en el que se ha producido el enterramiento; un gran número de esqueletos amontonados en una fosa puede sugerir que se trata de víctimas de una plaga, mientras que el enterramiento aislado de un cráneo podría quizá indicar un enterramiento de ritual. Así pues, es importante anotar el lugar de enterramiento con la máxima exactitud posible.

El universo de las muestras osteológicas humanas analizadas es procedente de diferentes sitios arqueológicos registrados en la geografía nacional. Este proceso permitió la localización de muchos espacios de enterramientos caracterizados como: Cementerios, Centro Ceremoniales, Espacios Sepulcrales Compartidos, Enterramientos Aislados; en estos sepulcros se descubrieron y se observaron diversas formas de enterramientos, costumbres atípicas, paquetes de restos humanos y especímenes que posiblemente fueron amarrados y desmembrados. Se han hurgado tumbas conteniendo restos humanos pertenecientes a varios individuos, asociados a restos fáunicos y objetos que conforman su ajuar funerario, también se han excavados áreas de enterramiento para la población aborigen de elevado estatus social, como es el registró de una sepultura de un Sukio con ofrendas de un incensario y colgante de Jade con forma de hacha y una Tumba de Cajón también conocida como Tumba de Cancel que contenían restos humanos de dos mujeres con ofrendas de Ocre rojo y otros indicativos de alto rango social, ubicada cronológicamente Periodo Tempisque-500-300 a.J.C, (García, 2017).

Esta gama de elementos antrópicos culturales puede sugerir marcas de referencias culturales, principalmente del estatus social de la persona; como el de un espécimen posiblemente anciano con ofrendas de Jade. En el mismo contexto arqueológico se reporta el hallazgo de un paquete de huesos humanos, entre los cuales hay un espécimen que en base a las características del cráneo corresponde al sexo masculino y parece haber sido desmembrado y se encuentran aso- 
ciados a restos zoo arqueológicos. Los dientes presentan un desgaste en forma de $\mathrm{V}$ o cavitados; probablemente se trata de un arreglo en los dientes incisivos inferiores, estas marcas indican elementos antropológicos de diferenciación social en el estatus del individuo.

\section{Análisis de Laboratorio}

El proceso de análisis de antropología física en laboratorio consiste en la limpieza física de los esqueletos, es necesario la eliminación de tierra en la mayor medida de lo posible, lavar con agua si la muestra lo permite, articular los restos fragmentados, hacer medidas biométricas, clasificación de la muestra por partes anatómicas, observación de afectaciones por patologías, traumas, culturales, desgaste dental, toma de notas, fotografías. Siempre que sea posible es aconsejable familiarizarse directamente con los huesos, tener un buen conocimiento de la morfología general del esqueleto humano para poder reconocer los restos fragmentados. Es muy importante conocer los rasgos biomorfológicos de: El cráneo, la columna vertebral, las costillas y el esternón, las extremidades superiores, región pélvica y las extremidades superiores e inferiores, con este conocimiento básico es posible identificar las osamentas humanas, que proceden de inhumaciones bien definidas como los que aparecen mezclados. (Brothwell, 1993).

El universo de la muestra consiste en más de 400 especímenes excavados y exhumados en diferentes regiones de país, el estado de conservación de las fracciones esqueléticas de cada uno de los individuos es variable desde aceptable, bueno, pésimo, en algunos casos se le aplicaron técnicas de restauración consistente en consolidación utilizando pequeñas cantidades de pegamento soluble en agua. Los análisis se realizaron de acuerdo a las porciones anatómicas, recolectada tomando en cuenta su estado de conservación, en primer lugar: Cráneo, Columna vertebral, Costillas y Esternón, Extremidades Superiores e Inferiores y Región Pélvica.

Entre los casos más relevantes de los especímenes analizados están los que proceden del yacimiento Los Placeres, Managua. Se trata de dos individuos asociados al sexo femenino, los análisis bioculturales sugieren que la forma de enterramiento de las dos, conspicuo pues comparten el mismo espacio sepulcral, el mismo tipo de indumentaria (ofrendas), las colocaron en la misma orientación y posición, con elementos culturales controlados sólo por la elite como es el caso del "Ocre" precolombino. Entonces este conjunto de elementos antropológicos culturales nos indica una posible sucesión de poder controlado por mujeres "Jefas, lideresas o Caciques" con cierto grado de parentesco.

Este análisis de estos restos y su contexto arqueológico permite interpretar los roles sociopolíticos de algunos grupos donde la matrifocalidad era más representativa que el patriarcado, a diferencia del sistema colonialista caracterizado por ser racista y patriarcal.

Se analizó a un individuo que perdió todas sus piezas dentales en vida y a corta edad, sólo hay evidencias de alvéolos abiertos en los Pm1 - lado derecho y Pm2 - lado izquierdo, con la presencia de un Incisivo lateral izquierdo con problema patológico (Tártaro). El cráneo muestra deformación antero posterior pronunciada, anomalías óseas que se producen como consecuencia de atarles la cabeza a los niños a una tabla.

Entre los años de 1998 al 2001, se desarrollaron investigaciones en el sitio de León de Imabite, se desenterraron más 150 especímenes obteniendo valiosas informaciones bioculturales sobre los patrones de enterramientos tanto de la época precolombina 
y colonial siglo XVI. Entre estos especímenes analizados encontramos los restos esqueléticos de una mujer perteneciente a los grupos sociales precolombinos con un orificio en el parietal izquierdo como resultado de una Cirugía -Trepanación primer caso reportado en la arqueología de la muerte en el país. Además, se observó a través de una lupa electrónica un conjunto de agujeros osteoporóticos causados por la osteoporosis, la operación fue realizada en esta misma región del cráneo.

En comunicación personal con el Dr, Enrique Guerzten Profesor de Patología en la Universidad de Virginia, USA, me compartió que ha realizado varias investigaciones vinculadas a las momias y las prácticas de trepanación por diferentes grupos culturales del Perú prehispánico.

Estos resultados son prueba contundente del conocimiento de los pueblos ancestrales, que no estaban insertos en el supuesto desarrollo de la medicina occidental, pero dejaron asombrados a los invasores, cuando se dieron cuenta que realizan estas cirugías con estuches de navajas de obsidiana, un vidrio de origen volcánico que puede tener igual o mayor filo que las herramientas de metal; su asombro fue mayor cuando vieron que las personas sobrevivían a estas operaciones. Así mismo, lo pude comprobar en el laboratorio con la muestra de cráneos, sobre todo la que procede de León Viejo, que presentan evidencias de cicatrizaciones de trepanaciones.

En los entierros prehispánicos de Marsella, en una zona que se localiza a unos 15 kilómetros de San Juan del Sur en la rivera de la costa del Pacífico con bosques de manglares que aún se conservan en la ecología del Istmo de Rivas. En este sitio se recopilaron restos óseos humanos de 5 individuos de la época precolombina, las fracciones esqueléticas mostraron alta fragilidad y una pigmentación muy blanca semejante al yeso, y evidencias de osteoporosis, estas anomalías probablemente se deben al tipo de alimentación rica fosforo por el consumo de peces, moluscos y bivalvos recolectados en los manglares. En varios de los entierros se encontraron ofrendas de estos moluscos. Según Legast (1998) los bivalvos se consideran como representaciones del sexo femenino y ciertos gasterópodos alargados como representaciones del sexo masculino.

Desde el punto de vista antropológico cultural se puede inferir que este tipo de enterramientos atípicos puede asociarse a un ritual, una actividad ceremonial y no se debe descartar la posibilidad de un sacrificio humano. Se analizó un caso con ofrendas funeraria consistentes en un caracol color rasado, varias cuentecillas de collar y restos fáunicos, se le identificó como el "Niño del caracol". Tanto las cuentas de colmillos y huesos como las de conchas marinas y los caracoles aparecen en gran mayoría en los entierros de mujeres e Infantes (Legast, 1998).

En el Barrio La Cruz, San Marcos - Carazo encontramos el símbolo de la cruz, formado con fracciones esqueléticas humanas, este es un elemento que está representado en los petroglifos, casi siempre está asociado a la altura y el agua, también se manifiesta como motivos iconográficos en la cerámica precolombina, en las figurillas humanas que representan al Dios de la lluvia de los pueblos Mesoamericanos conocido como Tlaloc, está presente en los tejidos, en las monumentales estatuas y otras manifestaciones artísticas de nuestros pueblos ancestrales.

Descodificando todos estos elementos antropoculturales descubiertos en su contexto arqueológicos y tomando en cuenta las características bioambientales de estos espacios geográficos, podemos sugerir que estas evidencias descubiertas en el Barrio La Cruz están vinculadas a un sacrificio humano o ritual en honor al Dios de la lluvia, lo que constituye una evidencia de que en este período iniciaron la agricultura y por tal, también iniciaron las fiestas y rituales religiosos agrícolas. Estos 
datos testifican sobre el mundo de creencias cosmogónicas, sus costumbres, creencias, mitos y ritos que tejían el entramado de sus prácticas por la fe y la espiritualidad, respetuosos de la Pachamama, nuestra madre tierra.

\section{Información biométrica}

Determinar la estatura: Para hacer la estimación de la estatura de un individuo o grupos de individuos, pertenecientes a comunidades pretéritas hay que tener en cuenta cuatro principios antropológicos básicos relativos a la altura:

Primero: La altura de un individuo aumenta hasta alcanzar la edad adulta y decrece conforme se acerca la senectud.

Segundo: Dentro de una misma población ya sea homogénea o mezclada se encontrará un considerable grado de variación en la estatura.

Tercero: La estatura media de una serie de poblaciones puede diferir ampliamente una de otra, pero cuando se considera la distribución general de la estatura dentro de cada grupo, todos los grupos presentan en común un determinado porcentaje de altura. Cuarto: La estatura media de las mujeres es menor que la de los hombres, cualquiera que sea el grupo.

Los estudios de antropología física en la muestra estudiada han demostrado en un 90\% que la estatura de una persona viene dictada por la herencia, mientras que los factores ambientales como la alimentación y el clima son responsables del otro 10\%. (Bass, 1996). De acuerdo a las técnicas modernas, podemos afirmar que los huesos diagnósticos para conocer la estatura de un individuo son los huesos largos (fémur y tibias). Pero es necesario tomar los datos biométricos de los restos óseos humanos en proceso de análisis para obtener mejores resultados.

El patrón biométrico del cráneo de las poblaciones originarias de América es bastante homogéneo, en el caso de la muestra analizada en el país, se obtuvieron las siguientes dimensiones: Altura desde la barbilla hasta el centro del cráneo $19 \mathrm{~cm}$, altura desde el Gonio hasta el Bregma $14 \mathrm{~cm}$, altura desde el Naso hasta el Frontal, ancho desde el Frontal hasta la Lambda $21 \mathrm{~cm}$, ancho desde el Mental hasta el Lambda $22 \mathrm{~cm}$. El grosor promedio del cráneo varía de 6.6 a $7.2 \mathrm{~mm}$.

La muestra analizada ha permitido saber que la estatura promedio de las mujeres era de 1.50 a $1.55 \mathrm{~cm}$ de altura y la de los hombres oscilaba entre 1.65 y 1.70. Aunque en ambos casos había excepciones, en el sitio los placeres se registró el enterramiento de una mujer que tenía como ajuar funerario un paquete de agujas de tejer elaboradas con espinas de pescado marino, esta mujer, de acuerdo al tamaño de su fémur y tibia media $170 \mathrm{~cm}$ aproximadamente.

Determinación del sexo: Para determinar el sexo de un espécimen en estudio es importante tomar en cuenta y analizar la morfología de las fracciones esqueléticas más diagnósticas como el cráneo, suturas craneanas, pelvis, escotadura ciática, el surco pre auricular, los rebordes supra orbitales, la cresta occipital, apófisis mastoidea y huesos largos. La morfología de mayor relevancia para determinar el sexo es la pelvis pues proporciona la información más fiable de cara a la determinación del sexo y es probable que pueda alcanzar de un 90 a un $92 \%$ de exactitud. En su conjunto la pelvis masculina es más robusta con impresiones musculares bien marcadas, la profundidad de la sínfisis del pubis es por lo general mayor en el hombre, la apófisis mastoidea es mayor en el hombre, el agujero obturador tiene mayor tamaño en el hombre y presenta un contorno más bien oval, mientras que en la mujer 
es más pequeño y de una forma más triangular, la escotadura ciática es más pequeña en el hombre. Estos rasgos biológicos son excelentes características diagnósticas. (Bass., 1995)

En base a la biometría del cráneo, la morfología de la apófisis mastoidea y a la escotadura ciática en la pelvis se puede afirmar con alto grado de probabilidad el sexo de un individuo.

En la muestra ósea prehispánica tenemos reportes de $50 \%$ de mujeres, $30 \%$ hombres y un $20 \%$ de infantes, esto nos ayuda a reconstruir la demografía de estos pueblos en la época pre colonial. Los principales datos nos indican que las mujeres estaban desempeñando roles de poder socio político, roles económicos en actividades asociadas a la recolección y producción de alimentos, también a la producción de vestimentas y desarrollo artístico y en los aspectos ceremoniales o espirituales como el contexto de las estatuarias del Sitio El Salto en Juigalpa, donde 10 estatuas que representan mujeres forman un semicírculo en adoración al este, donde nace el sol y solo hay representación del sexo masculino por una estatua que mira hacia donde se oculta el sol. En el caso de los hombres se obtuvo datos de su desempeño como sukios, guerreros, cazadores a los que pusieron puntas de lanza o hachas como ofrendas, también fueron pescadores y recolectores.

Determinación de la edad: Para determinar la edad en individuos adultos se toman en cuenta rasgos morfológicos en el cráneo, como el grado de fusión de las suturas craneanas y el grado de desgaste de los molares principalmente. En un cráneo en buen estado de conservación que se puedan observar las suturas craneanas, la dentadura en la maxila y la mandíbula cuando está completa; y se puede determinar si los dientes son temporales o si la dentadura es permanentes o de un individuo adulto y en segundo lugar el desgaste casi total de sus molares. El estudio de los dientes en el hombre antiguo es tan importante como el estudio métrico y morfológico de los huesos del cráneo. Dado que los dientes son particularmente resistentes a la descomposición una vez enterrados, sobreviven en algunos suelos mucho más tiempo que los huesos. Los dientes son por lo tanto de un valor considerable para estimar la edad media de las poblaciones del pasado. (Brothwell, 1987.)

El desgaste dental se puede definir como la pérdida de la sustancia de los dientes durante la mistificación debido a la fricción de una superficie dentaria con otra. Así como el efecto abrasivo de las sustancias duras que pueda contener el alimento. (Campbell, 1939).

Las edades determinadas en la muestra indican que el promedio de vida de las mujeres era de 40 años con algunas excepciones, como el caso de mujeres registradas en yacimientos arqueológicos localizados en el barrio Las Torres y en Los Placeres que murieron después de la quinta década. En los hombres indican un lapso de vida de entre los 40 a 50 años, también con variantes como el sukio de Los Placeres que pasaba de la sesta década.

Patologías y elementos culturales: Las principales patologías encontradas tanto en hombres como en mujeres fue el tártaro, las caries, artritis, osteoporosis. También se observó una característica cultural denominada dientes en forma de pala, se le llama así a una concavidad de la cara interna de los dientes incisivos que presentan el aspecto de pala, este es un rasgo genético de las poblaciones precolombinas de América en un $90 \%$ de los individuos. Resultados Bioculturales de los restos Humanos excavados en el Convento de San Francisco Quito Ecuador (Ubelacker, 1994 ).

Pérdidas dentales: Una de las observaciones más comunes en el análisis de la muestra dental es que los individuos perdían de 2 a 4 piezas dentales antes de morir, a temprana edad. Fue notorio en muestra correspondientes a las mujeres la perdida hasta de 5 piezas dentales principalmente incisivos y premolares, posi- 
blemente a causa del uso que le daban a su dentadura en sus actividades domestica cotidianas como al momento de tejer o hilar utilizaba sus diente como herramienta, para prensar y sostener.

Descalcificaciones óseas: En el universo de la muestra muchos restos óseos presentan evidencias de descalcificación en el cráneo, huesos largos, vertebras. Esta patología se caracteriza por una fina porosidad en los huesos y con más evidencia en los huesos planos, posiblemente esta enfermedad está asociada a la desnutrición, parasitismo y factores dietéticos. Algunos especialistas sugieren que puede estar asociados al raquitismo, factores de anemia y deficiencia de hierro.

El estudio Biométrico y bioantropológicos en las muestras osteológicas procedentes de las excavaciones arqueológicas que se realizan en diferentes regiones del país debe de ser un requisito primario para los investigadores ya que a través de los análisis osteológicos se obtienen importantes datos bioculturales de las poblaciones pretéritas.

Una diferencia biológica epidemiológica obvia entre los Periodos Históricos y Prehistóricos, es el impacto ocasionado por la introducción de las enfermedades europeas. Los anales históricos documentan que las plagas de viruelas, malaria, tifus, sarampión, y una gran variedad de otras enfermedades mortales, fueros introducidos en las Américas por los europeos, con un resultado devastador para las poblaciones aborígenes del continente (Ubelacker, 1994).

En Nicaragua, así como en casi todas las regiones de las Américas, estas enfermedades nuevas produjeron al causar epidemia, una gran mortalidad y como consecuencia la rotura social y económicas. No hay ninguna duda de que se ocasionó una gran pérdida de vida; sin embargo, las inscripciones históricas no detallan la magnitud de esta mortalidad, o la frecuencia en que se dieron estas enfer- medades a lo largo del Periodo Colonial.

Deformación cultural craneana: Son marcas o evidencias de afectaciones que se observan en los restos óseos causadas de forma intencional por un individuo en base a sus costumbres culturales. La deformación craneana intencional es un signo social de pertenencia a un grupo impreso de una manera indeleble en los huesos, se presentó con una gran popularidad durante el denominado Periodo Formativo en la América Nuclear y luego se extendió en otras regiones variables, a las poblaciones de casi todo el Continente. No cabe la menor duda de que esta práctica jugó un papel importante como indicador de pueblos y jerarquías dentro de la organización social de la América precolombina. Los estudios de J. Imbelloni. T. D. Stewart y P. Weiss., lograron identificar y describir los tipos de deformación craneana que se han observado en el Continente, su distribución geográfica y también una parte importante de sus filiaciones culturales.

Ajuares funerarios: Las ofrendas funerarias dicen mucho de los patrones de vida de los pueblos ancestrales. Su creencia en una vida espiritual los llevaba a creer que sus seres queridos debían llevar a la tumba, alimentos, armas, vestimentas, adornos corporales entre otros objetos que formaban parte de sus pertenencias en su vida física. De tal manera que las ofrendas pueden determinar tipos de alimentación, estatus social, practicas ceremoniales, conocimientos y saberes.

En la muestra se logró identificar actividades como los tejidos a través de ofrendas de agujas, a los / las pescadores les colocaban ruecas, si eran de estatus, les depositaban Ocre rojo y los restos zoo arqueológicos han permitido reconstruir la dieta a base de granos, carnes obtenidas de mamíferos, peces, aves, reptiles y moluscos. En el aspecto ceremonial o creencias espirituales a los guías o sukios les ponían colgantes de jade o de oro. Finalmente, estos objetos reconstruyen los tipos 
de vajillas o utensilios domésticos, ceremoniales y de intercambio comercial.

Patrones Alimenticios: Los análisis de Antropología Física han permiten obtener conocimiento los vínculos Etnozoológicos y Etnobotánicas, podemos inferir sobre las especies de animales y vegetales que formaban parte de la dieta cotidiana de las comunidades y sociedades pretéritas. Haciendo investigaciones bibliográficas y apoyándonos en otros trabajos científicos sobre los patrones alimenticios en la Nicaragua precolombina como los realizados con la muestra del Ostional, Rivas en 1995 podemos hacer referencia a cerca de las especies botánicas y faunísticas que estuvieron aprovechando las poblaciones de Nicaragua para su alimentación.

La reconstrucción del régimen alimenticio de las poblaciones de Nicaragua prehispánica es sumamente importante, ya que, según los datos que resulten, podemos conocer si establecieron o no patrones y estrategias de subsistencias, es decir, algunos tipos de prácticas culturales, lo que implica conocer la dinámica y complejidad social de la gente que tuvo como habitad el espacio geográfico de nuestro territorio. Existen diferentes métodos de investigación para realizar estudios del régimen alimenticio de las poblaciones originarias, incluyendo el estudio de utensilios domésticos y el análisis de iconografía en los artefactos. También aplicando las técnicas de paleo etnobotánica, el estudio de rasgos micro bióticos, polen de fitolitos y análisis de restos zoo arqueológicos.

Los posibles recursos alimenticios de las poblaciones de Nicaragua y sus valores nutricionales aproximados $\wedge$ (delta) $13 \mathrm{C} \mathrm{y} \wedge 15 \mathrm{~N}$ para la baja Centro América región donde se encuentra emplazado el territorio nacional, están sustentados por el consumo de especies botánicas como yerbas, frutos, tubérculos, cucurbitáceas, maíz, amaranto, nopales, epifitas, maguey, piña, legumbres. Consumían ci- ertos mamíferos, peces, aves, algunos reptiles y molusco bivalvo y gasterópodos. Solamente con un exhaustivo análisis de restos osteológicos humanos, se podría obtener una verdadera información acerca de los patrones alimenticios y los patrones de asentamientos de la Nicaragua prehistórica. (Brandy Wheeler, Ramiro García Vásquez, Amanda Diers) en F. W. Lange, pág. 163-165. 1996.

\section{Análisis de los Resultados}

- Después de haber realizado los análisis "In situ" y en el laboratorio de los restos humanos se han obtenido los siguientes resultados:

- Obtuvimos de los restos humanos una valiosa información bioantropológicas- biométrica de los grupos sociales que se emplazaron en nuestro territorio.

- Los estudios permitieron obtener un hiato de información vinculada con la etnozoología y la etnobotánica, conociendo las especies animal y vegetal que estuvieron consumiendo coma parte de su dieta cotidiana.

- Los análisis permitieron comprobar que los restos zoo arqueológicos se estaban utilizando como recursos ceremoniales ya que se depositaban a sus difuntos al momento de ser sepultado.

- Estos análisis ha permitido conocer algunos problemas patológicos que estuvieron padeciendo la población prehispánica (La artritis, la caries y tártaro parecen ser las más comunes), en especial en la osamenta de las mujeres.

- Los análisis de antropología física permitieron comprobar que estuvieron practicando al menos 10 formas de enterramiento y utilizaban los mismos recursos como ofrendas funerarias que depositaban a sus difuntos parientes.

- Mediante los análisis de todo el universo de las muestras osteológicas de los diferentes 
especímenes, encontramos una diversidad de objetos culturales que estaban asociados a las osamentas como parte del Ajuar Funerario, esta diversidad en las ofrenda que se le depositaba a cada individuo, permite inferir elementos de diferenciación socia, por ejemplo el individua con ofrendadas de Jade, oro o cerámicas decoradas, collares dientes de animales, humanos y moluscos, sugiere que se trata de un personaje de elite, muy Importante dentro de su comunidad o grupo social de la época.

Estos resultados nos sugieren que nuestros antepasados tenían una organización social altamente desarrollada para su época, vivían en un modelo de propiedad comunitaria, con una economía de consumo familiar-comunal bien establecida por sus grandes conocimientos de la agricultura, lo que les permitía producir los alimentos que requerían para poder establecerse como grupos sedentarios; desarrollaron las artes al elaborar vajillas de barro y lítica, pintaban, tallaban, esculpían. Su cosmogonía espiritual era politeísta por el gran respeto que tenían a la naturaleza, al sol, a la lluvia, al viento, al mar, la noche, la vida y la muerte.

Al llegar los invasores y establecer su modelo colonizador, hegemónico, racista, patriarcal, justificaron todas sus vejámenes y saqueos en que los pueblos originarios tenían una cultura inferior a la de ellos, afirmaron que no los reconocían como humanos, los esclavizaron y diezmaron, impusieron la mescla biológica por medio de la violencia y garantizaron la imposición ideológica al prohibirles hablar en sus propios idiomas, de esta manera la colonización has sobrevivido hasta nuestros días.

A esto es lo que Beorlegui llama "derecho a la diferencia" planteado como un disenso instalado no desde la satisfacción y la insolidaridad, sino desde la de $\neg$ fensa de los derechos de las minorías marginadas y de todos los excluidos por los poderes hegemónicos (Beorlegui, 2006: 856). Actualmente tener las características bioculturales que identifiqué en esta muestra estudiada es motivo de señalamientos de inferioridad, pero no solo se recibe de parte del neocolonizador extranjero, sino que ahora el propio descendiente considera inferiores a sus hermanos de sangre y patria porque es portador de la herencia colonial.

La filosofía liberadora desarrolla su crítica a la razón moderna en nombre de una razón diferencial y en este sentido entiende que "desde la mera y única insistencia en el derecho a discrepar y a ser diferente" (Beorlegui, 2006: 879) no se favorece a los explotados y dominados. Estos "grupos de diferentes" que en términos de Dus $\neg$ sel (2003) son "víctimas de la Modernidad", aspiran a proponer la cons $\neg$ trucción de un nuevo orden global, donde las orientaciones univer $\neg$ sales de justicia y verdad sean configuradas de una manera distinta. Por un lado, las víctimas de la "irracionalidad" de la modernidad, para Dussel (2003) evidencian la "otra cara" negada del proyecto de la modernidad colonial. Por el otro, es en la negación del "mito ci $\neg$ vilizatorio", de este proyecto (moderno, luego emancipador, liberal, modernizador, desarrollista, hoy neoliberal) y desde el develamien-to de su violencia, donde y cuando es posible edificar una "razón liberadora". Es en este acto epistemológico-político se cita:

(...) cuando se define la "falacia desarrollista" del proceso de mo $\neg$ dernización hegemónico [...] cuando se descubre la dignidad del Otro (de la otra cultura, del otro sexo y género, etcétera); cuando se declara inocentes a las víctimas desde la afirmación de su Alteridad como Identidad en la Exterioridad... (Dussel, 2003: $50)$.

Por su parte, Mignolo recupera esta radicalización crítica de Dussel desde su perspectiva de denuncia de la "cara genocida" del colonialismo (Mignolo, 2003: 30), entendiendo al pensamiento liberador como aquel que teniendo que pensarse en la "intersección de las experiencias que el saber de la modernidad relegó a objetos del colonialismo", se corresponde con 
un "sujeto que no quiera que le den la libertad, sino que quiera tomarla por sí mismo, construyendo su propio proyecto en un paradigma otro" . (Dussel \& Mignolo, 2003).

\section{Conclusión}

La antropología física nos ha permitido reconocer a nuestros pueblos originarios, Lencas, Chorotegas, Chondatl, Nicaraos, Sutiabas, Mayagnas, Ramas, Miskitos entre otros. Este reconocimiento es primeramente físico - biológico, pero estos análisis permitieron llegar hasta el conocimiento de su cultura material e inmaterial. Con estos resultados podemos divulgar que descendemos de multiculturas milenarias que nos legaron un gran acervo cultural que solo puede hacernos sentir orgullo, a pesar de que otros grupos en su intención de dominarnos y someternos han querido hacernos desaparecer toda esta memoria colectiva de saberes con raíces originarias.

En Nicaragua como en toda Mesoamérica seguimos conservando los rasgos biológicos característicos de nuestros grupos étnicos del pasado, compartiendo los mismos patrones biológicos como estatura, color de piel, del cabello,

Desde la invasión del colonialismo hasta la actualidad, toda la historia que nos cuentan desde los cronistas, hasta los hispanófilos modernos está colonizada, manejada, mal contada, manipulada y son estos los principales responsables de que este modelo hegemónico colonizador aun sobreviva en nuestros países, son ellos los que siguen repitiendo que Europa es el Centro del Mundo y continúan dando vida al mito de una supuesta civilización, usada como instrumento para seguir aplicando las políticas colonizadoras neoliberales.
El trabajo de la Antropología Física es de enorme interés y muestra una metodología de aproximación científica al conocimiento de las verdades del pasado que nos parece un camino seguro para llegar a un conocimiento de nuestras verdaderas culturas dejando a un lado las historiografías ajenas, sentimientos más o menos manipulados en uno y otro sentido, o repeticiones de "verdades" aceptadas sin suficientes críticas, que es preciso revisar.

Desde la invasión del colonialismo hasta la actualidad, toda la historia que nos cuentan desde los cronistas, hasta los hispanófilos modernos está colonizada, manejada, mal contada, manipulada y son estos los principales responsables de que este modelo hegemónico colonizador aun sobreviva en nuestros países, son ellos los que siguen repitiendo que Europa es el Centro del Mundo y continúan dando vida al mito de una supuesta civilización, usada como instrumento para seguir aplicando las políticas colonizadoras neoliberales. 
Finalmente invito a la reflexión sobre este fenómeno mental y sociocultural que es la colonización para que, al conocernos y reconocernos, nos valoremos, nos comprometamos con nuestros antepasados y con las generaciones del futuro, para esto debemos empezar ahora mis-

\section{Bibliográfica}

Bass, W. M. (1996). Human Osteology. Missouri: Fourth Edition.

Bass., W. M. (1995). Manual de Osteología. Missouri: Library of Congreso Cataloging- in-Publication

Brothwell, D. R. (1993). Desenterrando Huesos. Madrid: FCE/España, 1993.

Dussel, E., \& Mignolo, W. (2003). El proyecto descolonial hacia una EpistEMología otra $\mathrm{d} E$ las ciEncias social E s En aM érica latina. S/C: S/E.

García, R. (18 de julio de 2017). http://www. temasnicas.net/split114/mujerguerrera.pdf. Obtenido de http://www.temasnicas.net/ split114/mujerguerrera.pdf: http://www. temasnicas.net mo, con la convicción que podemos vivir en una América descolonizada, orgullosos de lo que somos, porque como lo comprobó el Padre Tomás Ruiz Romero; ien la tumba todos y todas somos iguales!

Lange, F. W. (1995). DESCUBRIENDO LAS HUELLAS DE NUESTROS ANTEPASADOS. . Managua: Imprimatur Arte Gráfica. .

Legast, A. (1998). Boletin de Arqueología. Fundación de Investigaciones Arqueologicas Nacionales. Santa Fe de Bogotá: Guadalupe, LTEDA.

Ubelacker, D. H. (1994 ). Biología de los restos humanos hallados en el Convento San Francisco, Quito-Ecuador. Quito. Quito: La Huella Impresores. .

Valls, A. (1985). Historia de la Antropología. Fundamentos de la evolución y de la variabilidad biológica. S/C: S/E.

Ramiro García Vásquez

Realizó estudios de Licenciatura en Ciencias de la Educación con Mención en Biología (UNAN-Managua). Posteriormente hizo estudios Técnicos en el extranjero (México, Panamá, Suecia, Dinamarca) se especializó en Paleontología, Arqueología y Antropología Física. Entre 1994 y 2013 se desempeñó como Responsable del Departamento de Investigaciones Antropológicas del Museo Nacional de Nicaragua, realizó investigaciones paleontológicas, antropológicas y arqueológicas a nivel nacional. En el año 2001 fue condecorado con la Medalla Diocleciano Chaves y Las Llaves del Museo Nacional de Nicaragua en reconocimiento a su labor científica. Es miembro Honorario de la Academia de Geografía e Historia de Nicaragua. En los últimos 15 años se ha desempeñado como Consultor Cultural a nivel nacional e internacional. 